\title{
Training of the Hypothesis Thinking Mode in the Basic Teaching of Painting in Visual Design
}

\author{
Yuanming Zhang \\ Zhuhai College of Jilin University \\ Zhuhai, China
}

\begin{abstract}
The biggest difference between design and painting (art) is that the design process has no concrete reference object, and the picture image is non-real image. It requires designers to create without foundation or paint without reference object. It is the creative thinking we say at ordinary times. It is more accurate to call it the ability of hypothesis which is the most core basic skill in conceptual design. Then the next key step is to select the depicting methods to realize the hypothesis. It is why we spend a lot of time on basic skills training facing models and landscapes in class, but we are still blank when we design. The creative process of visual design is a process turning abstract thinking based on visual thinking into visual creative through scheduled conceptual associations. Logical thinking plays the role of supervisor in the whole creation.
\end{abstract}

Keywords—basic teaching; hypothesis thinking mode; training

\section{INTRODUCTION}

In the teaching of basic courses in visual design we often encounter such a problem: students with solid basic skills are hard in creation of design after entering higher grades, and they couldn't use their basis painting skills on creation of design. They are adept in painting or sketching, but they have no idea in creation of conceptual design. The basic course of painting hasn't played a due role in the visual professional course. This phenomenon has become a common problem in the design colleges and universities at different levels. It has confused many teachers and students. Even some professional colleges and universities begin to question the necessity of setting up the basic course of painting in visual design. The author discusses and analyzes the phenomenon, and uses personal teaching practice to find a way to solve this problem.

\section{The Current Teaching Status of Basic Painting COURSE IN DOMESTIC Visual COMMUNICATION}

Fine art colleges and universities have arranged basic painting course for visual design with different teaching hours in the first year. The basic teachings of art specialty and visual design have been using the same teaching mode, still life, figures and landscape sketch. Works are mainly reappearing descriptions. From the perspective of teaching effect, the content settings of basic course are not associated with professional courses in addition to belonging to visual art in class structure. Students who have clear major orientation want to expose to knowledge of their major as soon as possible. They don't reach the preset study effect from basic courses of visual design, and their learning objectives are not clear, so they are not enthusiastic in learning. In order to deal with the above problems, some art colleges and universities use design sketch and design color to carry on the teaching reform, and the final result still stays on the change of course name.

\section{The REAsons Why THE PRACTICE OF BASIC PAINTING COURSE IN ART IS NOT SUITABLE FOR VISUAL DESIGN}

In the late 19th century and early 20th century, modern art was divided into two major directions, painting and design. Design comes from painting, which has already been a common sense, so a lot of people think that design is part of painting, and people who can draw can design. The reason for it is because people have no deep understanding and analysis about causes of design and causes of Postimpressionism, Fauvism, later Abstract Expressionism and Bauhaus. The Western paintings before the Impressionist mainly were reproduction art of still life, landscape and figures paintings. The picture pursues to depict the shape, colors and even mental state of object, which is just the presentation of material aspects. From the Post-impressionism to the birth of Bauhaus, artists mainly painted to express their own opinions and concepts. They usually expressed their feelings through depicting object from their special perceptions. At this time the depicting object had become a manifestation of emotion and concept and a symbol of the picture rather than the object itself. When the modern art developed to the times of Mondrian, Kandinsky and Miro, the depicting object of painting was completely changed from "substance" into "symbols" like dot, line and plane, and even color block. Works completely get rid of the subjective creation of natural objects in reality. Symbolic modeling elements became the media to express personal ideas. At this time design was officially born. Design originates from painting, but it is also born out of painting. Works mostly expressed personal concepts of artists, so that it entered into a new development direction.

Compared with sketching and reproduction of painting, design is completely a creation developing from nothing. Their pursuits are different and even contrary. Painting pursues to maximize the possibilities, while design pursues to minimize the possibilities. The acme of painting is to be understood by fewer and fewer people, while the acme of painting is to be understood by more and more people. Free painting is a good painting. Reasonable design is a good design. Painting is mostly related to culture, while design is largely related to 
science and technology. Painting often is associated with sociology, psychology and other disciplines for long-term development. The majority of artists are active in reading books of philosophy, so their artistic works are given with ideological and cultural depth. Culture could direct artists to create, for instance, Surrealism Flagman Salvador Dali's masterpiece The Persistence of Memory. There are many symbolic symbols, like soft clock and ant, in the picture. The two images were repeated in later works of Dali, and it was a repeated scene in Dali's dreams. Great psychologist Sigmund Freud in the 20th century proposed the word of "subconscious". His researches showed that subconscious was fully reflected in one's dreams. Things in dream are of reason which is the subconscious of the person. When Dali knew subconscious, he knew his painting direction clearly. Dali has created a series of works according to his subconscious, and works in this period are his representatives. Design seems to be far from the humanities. But with the involvement of science and technology, good designs will be outstanding. Buick has launched amphibious concept car. The upper part is a yacht, and the lower part is a car chassis. It is very modern, and has powerful functions. Concept car is divided into two types. The first is car already able to run, close to mass production. Its advanced technology has entered the test and gradually moved to practice. Generally in 5 years or so it can be put into production. The second car is only a conceptual model. It has advanced design, but because of the environment, the level of scientific research, cost and other reasons, it is just a research idea for the future development. This Buick amphibious car belongs to the second type. It can be seen that if there is no support of science and technology, the concept car will always be just a "concept".

The process of design is a process of narrowing reality and expectation. For example, if we want to design a better electric kettle, it is because the current kettle has a poor shape or has functional defects, and is not beautiful or comfortable. In this process designer first shall have a design expectation. He/she want to design certain style: science kettle, kettle with cultural connotations or something else. Then he/she needs to establish a set of logics: is it able to use maglev technology? What kind of style will I use? Heavy industry portfolio or other forms? To this step, we will find the biggest difference between design and painting is that design has no specific reference object, and its picture image is non-existing image. Design requires designers to have the ability to create without foundation or to paint without reference object, which is creative thinking we say at ordinary times. It is more accurate to call it hypothesis ability. This ability is the most basic skill in conceptual design. And then the key step is to select painting methods for the realization of hypothesis. It is why we spend a lot of time on training of basic skills confronting models and landscapes, but we still are blank in mind when we design. Painting needs reference objects, but design doesn't need models or reference objects. Students shall have the ability of hypothesis and technique of expression for paining object.

At this point, we found that the hypothesis thinking mode is the core of design, and idea is before design. Traditional training method with model, landscape or picture as reference object cannot provide students with environment for hypothesis thinking. The basic course of painting is not suitable for visual design.

\section{How to Cultivate The ABILITy OF HypOthesis THINKING}

In order to achieve the purpose of training the hypothesis thinking of students, the basic classroom training should follow the following points:

\section{A. Help the Students Find Their Own Techniques of Expression}

This is the premise to design. Only grasping techniques of expression and coloring, students are able to express their ideas. For instance, if one is not familiar with tools of image software, he/she will meet technological obstacles in the process of painting and is impossible to design good works. Before entering the art academy students have already had some abilities to shape images with sketch and colors, but those abilities are far from enough. Even they can be obstacles of students to improve their painting ability. Before college entrance examination, students were given with modeled training in order to pass the examination. Teachers may tell students to use which colors to mix the color of apple and which colors to mix the color of grape, so students paint same apple and grapes every time. In this modeled study, students are passive to receive knowledge rather than actively express images. If students didn't grasp the laws of styling and coloring, they will have obstacles in expression. They cannot draw the images and mix the color in their mind, cannot find pleasure in painting and are not confident in painting, and even refuse to study. Influenced by the effect of the first impression, it is difficult for teachers to correct their mastered but inappropriate expression methods and ways of thinking. There is an urgent need for the students to solve the technical problems in the process of painting - to find their own way of painting.

There are two important reasons why students cannot find their own techniques of expression. The first reason is that students learn passively and practice less and are unable to enter into the expression scene. The second reason is that students only know a few methods and techniques of expression. Each person has different character and habit, so the expression skills used are also not same. In view of this problem, teachers should introduce expression techniques, painting tools and materials as many as possible in class, and ask students try to use different techniques of expression, tools and materials. You will find some students like to use water, some like color pencils, some like large fan brush, some like to make image full of emotional appeal, and some like to make image super realistic and lifelike. After finding their own techniques of expression, through intensive training, students will grasp techniques of expression and the overall rhythm of the picture. More important is that it can establish student's self-confidence, and stimulate the student's desire to express.

\section{B. Train Students' Hypothetical Thinking Mode}

1) The hypothesis training in the process of visual thinking: Teachers can put some common objects of daily life 
and ask students to find the beauty of them. Teachers can place some things, like newspapers, different kinds of fruits, water cups and a pair of shoes, and ask students to depict the objects they are interested in. Take the placement of shoes as an example. First, ask students to look them upward, downward and at eye level, and depict. Then ask students to act as director and ask them arrange plots about the placement of shoes. Ask students to depict the state of shoes in shoe box, in shop window before sale, when people try on, on the production line, when they are worn out and discarded, and do some other creative association training. And ask students to depict surrounding scenes in each picture.

First of all, ask students to depict same object from many angles. It can exercise students' comprehension ability, and then guide them to develop a multi-angle and threedimensional analysis habit. Secondly, arrange the depicting object in the context of story. It can fully train students' creative hypothesis ability and broaden the scope of imagination. It is the most important part in the training of creative thinking.

2) The creative training in abstract thinking process: Carry out the practice of making concrete image in the picture symbolized. Teachers provide students realistic works of old masters, and ask students to summarize the images in the picture in dot, line and plane. It is to guide students to transform from concrete thinking to abstract thinking. The images in visual design generally are concise, general and symbolic. Students should have the ability to feel the abstract through concrete image. The composition consciousness of dot, line and plane should be guided as soon as possible in the basic painting course, which is the sublimation of creative hypothesis thinking.

3) Logical thinking training: Logical thinking is an ignored aspect among many visual art creation proposers. Design can't be as free as art. In terms of graphic design, it should be with reasonable composition, particular color match, appropriate typeface and patterns. Good graphic design must be given with a "harmonious tension" in all aspects. Industrial design shall conform to the laws of physics. Many designers have a powerful and unconstrained style imagination, but they have no idea to realize it. We cannot say that this is not a very creative design, but in some aspects the unreasonable part equally leads to failure of design.

In the process of hypothesis thinking, logical thinking is reflected on two parts: the one is the reasoning logic thinking in the process of hypothesis. The other is the reasonable logic thinking to complete hypothesis. Students should have the logic thinking of completing a series of assumptions and ideas. Only in this way can the training of creative thinking be meaningful and valuable.

In the field of visual design, creation is a process of gradual improvement. From a psychological point of view, the psychological activities of creation include the visual thinking process and the process of abstract thinking. The starting point of the psychological activity of visual thinking is visual perception which is a relatively high-level psychological activity, higher than feeling and close to thinking. Visual perception allows us to gain a wealth of visual experience and personalized visual perception from our living environment, and improves perceptual integration ability with the accumulation of quantity. The training process of students finding their favorite depicting techniques is a psychological activity of visual thinking. Students gain experience and feelings from the training of artistic expression techniques. When they find their favorite techniques of expression, their integration ability will also be improved. This process starts from visual perception and ends by visual thinking. Visual perception makes visual thinking more deeply, and visually expresses the abstract creation of the brain. It is mainly manifested in visual sensitivity, image abstraction, cognitive ability and image expression ability etc. Visual thinking and non-vision are mutually influenced in the process of visual creation. We describe visual thinking as a specific and predetermined representation. The abstract thinking is a concept. Visual design creation process is the process of turning abstract thinking based on visual thinking to visual creation through concept of predetermined relevance. Logical thinking plays the role of supervisor in the process of the whole creative thinking of design.

\section{CONCLUSION}

It is very important to train students' hypothesis thinking mode in the basic teaching of painting in visual design. The hypothesis of thinking training task should be set on basic professional style, aesthetic ability and students' basic painting foundation. It is not wise to make hypothesis blindly, which will make training of hypothesis thinking lose professional foundation. The common artistic attributes of painting and design make the basic teaching of visual design difficult to gain outstanding achievements. In addition, a few teachers really understand the common characters and differences of the basics teachings of the two disciplines, which makes the basic teaching of painting in visual art become a difficulty in the teaching reform of current art education. The author believes that in the joint efforts of the teachers of fine arts, the basic teaching of the visual arts will achieve better results in training of hypothesis thinking mode.

\section{REFERENCES}

[1] Ding Ning: Art Psychology. Heilongiiang Fine Arts Publishing House, Harbin, 1994

[2] Rudolf Arnheim (America). Translated by Teng Shouyao. Arts and Visual Perception. Sichuan People's Publishing House, 1998.

[3] Ma Yongjian. 20 Handouts of Modernism Art. Shanghai Academy of Social Sciences Press, 2005.

[4] Li Zhiqiang. Reflection on the Teaching Reform of Basic Painting in Art Design in Universities and Colleges. Art Education, 2014.

[5] Hu Zhixiong. Discussion on the Basic Course of Painting and Art Design. Popular Literature and Art, 2010. 